\title{
ICTs as a mighty resource for cutting edge cities: case study - Genoa and its port
}

\author{
H. Ghiara \& G. Striglioni Ne’Tori \\ Faculty of Economics, University of Genoa, Italy
}

\begin{abstract}
Information and Communication Technologies are increasingly enhancing dayto-day operations and long-time programmes within the whole transportation sector. Furthermore, they allow for different modes of transport to be integrated in a more efficient way; not just among themselves, but at the same time with surrounding environments like cities, urban areas or more extended regions involved in transportation supply chains.

In February 2011 Genoa Port Authority, as a leading partner, began activities to create the ICT platform named MoS 24 (Motorways of the Sea 24). The main goal of the project is to create a unique information system connecting autonomous programmes, developed by different modes' transport operators, already operating along the multimodal Corridor 24 between Genoa (Italy) and Rotterdam (The Netherlands).

The city of Genoa, one of the main ports in the Mediterranean area, is directly involved with the project's development as a gateway for goods from the global market heading to the North European area and vice versa.

The core aim of this paper is to analyze how the city may improve its connectivity with the European transport network and obtain advantages from the smart use of trans-European ICT platforms.

Roles and ideas of the eleven players (both public and private) taking part in the operations will be considered as well. A deeper analysis will be shown through data and opinions collected during face-to-face interviews with partners' delegates.

Keywords: Information and Communication Technologies, multimodality, TransEuropean Transport Network (TEN-T), multimodal logistic platform, Comodality Promotion Centre (CPC).
\end{abstract}




\section{Introduction}

Nowadays, terms and concepts like global logistics, supply chain management, multimodal and door-to-door transport are widely recognized as priority keywords fully describing freight market's main features (Verhoeven [1], Notteboom and Rodrigue [2, 3], Ducruet and Notteboom [4]).

Focusing closer on the maritime sector, Haralambides [5] states that it is now more correct to analyze the competition of whole supply chains rather than that in a single port in order to better understand the trends and performances shown by single productive units.

Since cooperation and partnership are essential to enforce a business, an extended glance analyzing the whole productive system is preferable to highlighting the real strengths and weaknesses conditioning the final product or service.

A direct consequence of this wide and complex landscape is an extremely intense use and development of information and communication technologies (ICTs). The more extensive market that traders are dealing with, the better means of communications and sharing information must be put to use among players.

Since intermodal transport is more data-intensive than conventional transport, the role of ICTs in transport is of crucial importance (Campanai et al. [6]).

Reasons are multiple. First of all an accurate use of specific ICTs leads to more customer-oriented services and allows a better integration among different links within the transportation chain. Then global efficiency along the entire supply chain can be dramatically enhanced. Last but not least whole costs could be potentially cut down as a direct consequence of better management.

As essential links for global commerce, ports are directly involved in ICTs' development.

\section{E-ports' rise}

As stated above, ports work in quite a complicated environment, composed of several players, both public and private, who need to interoperate to achieve their own goals.

Port performances are not determined any more just by efficiency along quays or inside warehouses, but how smoothly ports are integrated within transport networks.

Dealing with other people is strictly synonymous with communicating with them, so that ICTs are a powerful key to enhance port activities.

Within port business, operations' scheduling, information flow's management, communications, security management and Customs operations are fields which ICTs are mainly used in; to name but a few (Campanai et al. [6], Navarro et al. [7]).

Nonetheless ICTs alone are not enough for port development. They could not even be concretely applied if not supported by adequate infrastructures allowing a good physical interconnectivity between ports and other nodes within the transport chain. ICTs' development must move forward together with a 
continuous improvement on an infrastructural, technological and organisational level to work at their full potential.

Nowadays, the most extended concepts, based on ICT tools, to support the modernization of the ports and trade facilitation are the "Port Community System" and the "Single Window" (Navarro et al. [7]).

The former is defined by the European Port Community System Association (EPCSA) as a neutral and open electronic platform enabling an intelligent and secure exchange of information between public and private stakeholders in order to improve the efficiency and competitive position of the sea and airports' communities (EPCSA [8]). The latter, according to United Nations' definition, is a system that allows traders to lodge information with a single body to fulfil all import- or export-related regulatory requirements (United Nations [9]).

Both PCSs and SWs are direct reflections of the network concept. The more people are involved in a supply chain, the better it works if a good communication system has been put to use among them.

Single Window is potentially much more extended, geographically speaking, compared to a Port Community System, which is exclusively restricted to port related activities.

Nevertheless, there is no a unique way to build a Single Window environment (Navarro et al. [7]). So it would not be correct to try to find a universal outline.

Theoretically, a Single Window does not necessarily imply using high-tech information and communication technology (ICT), although for practical purposes it is usually better if governments do adopt ICTs for a Single Window (Koh Tat Tsen [10]).

Tangible proof of how a single window approach could enhance port activities and enlarge its network is provided by analyzing the Genoa Port Authority's experience of ICT's development.

\section{The MoS 24 Project}

\subsection{Project's analysis}

In February 2011, the Genoa Port Authority (GPA), as a leading partner, began activities to develop the MoS 24 Project together with an eleven player team, both public and private.

The main goal of the project, whose name comes up contracting together the Motorways of the sea and Corridor 24 (see 3.1.1), is creating a unique ICT multimodal linkage between Northern and Southern Europe by connecting virtually the Corridor 24 with Motorways of the sea within the Mediterranean basin (Port Authority of Genoa [11]).

In a nutshell, it means realizing an ICT platform able to embrace the existing programmes already used by different transport operators and public bodies along the Corridor 24 and shipping routes crossing the Mediterranean Sea. A sort of "big umbrella" covering and interconnecting separate systems in order to realize a single interface to plan, organize and check cargo shipments.

A unique electronic window to insert data into, to compare itineraries, execute borders' formalities and share significant information through. 


\subsubsection{Project's integration}

The MoS 24 Project is part of European Union initiatives aiming at enhancing an integrated, technology-led and user-friendly transport system among European countries (European Commission [12]) in order to realize a Trans-European Transport Network (TEN-T).

The project is complementary to another one, included within the TEN-T priority list, named Code 24. Its goal is the infrastructural development along the multimodal Corridor 24, connecting Genoa (Italy) and Rotterdam (The Netherlands).

Regarding what concerns the maritime side, the MoS 24 Project involves the Motorways of the sea framework, inserted within the TEN-T initiatives as well, whose aim is to introduce new intermodal maritime-based logistic chains in Europe, shifting cargo traffic from the road network to environmentally-friendly waterways (European Commission [12]).

\subsubsection{Project's configuration}

Geographically speaking, the project embraces six different macro regions (Pinasco et al. [13]):

1. Benelux (Belgium and Holland);

2. Germany;

3. Swiss (only considered as a transit region);

4. Italy (North West);

5. West Med (France/Spain);

6. South Med (Malta).

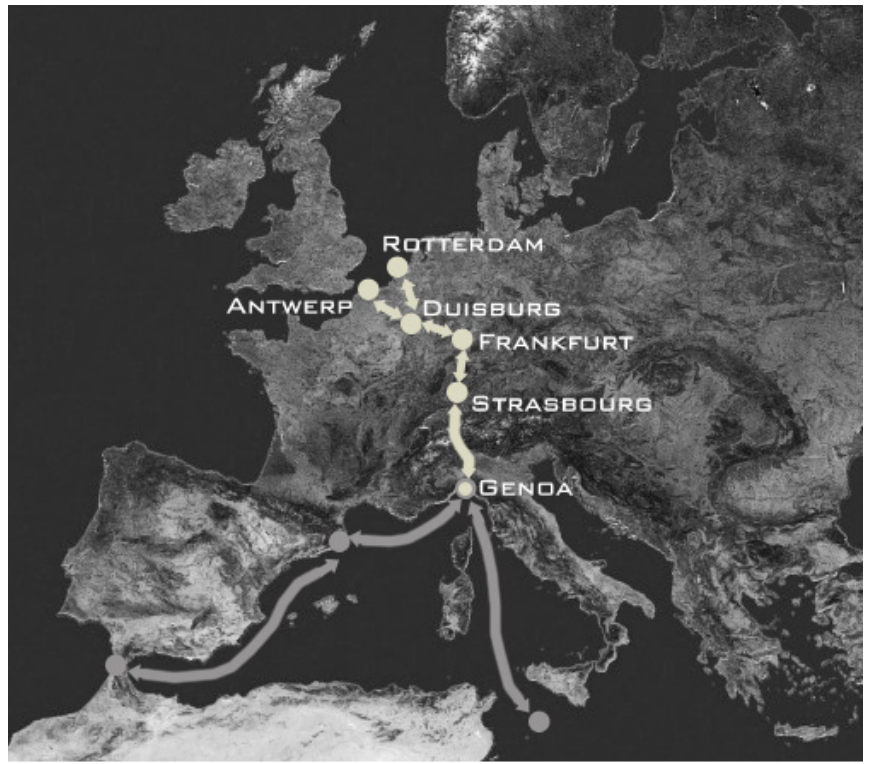

Figure 1: MoS 24 Project layout (source: Wikipedia; Graphics processing: Maria Montelatici). 
Only the first four regions are strictly included within Corridor 24. The last two take part in the project as marine links with the Port of Genoa and Motorways of the sea' integral part.

\subsubsection{State of the art}

The supposed ending date of the Project is December 2013.

The activities carried out so far can be divided into three different sections (Port Authority of Genoa [11]):

- Analysis of the context: a comprehensive study along Corridor 24 to research operational services in the relevant markets and infrastructural linkages.

- Interoperability and design of MoS 24 Platform: according to outcomes from the former activity, the platform has been designed.

- Implementation of MoS 24 demonstrator: platform's test through a prototype.

\subsection{The city of Genoa within the MoS 24 Project}

The city of Genoa is the core junction for project development; both on a geographical level and on a managerial one.

It is indeed located exactly half way between sea and land side within the MoS 24 layout (see figure 1).

For this reason it could become the exclusive gateway for northbound cargoes proceeding from the Mediterranean basin or, at a wider glance, from Asian markets. Or vice versa, it could be an efficient way out for European goods heading to the Mediterranean Sea or even farther to Asia.

The Port of Genoa could potentially be an exclusive link with North African transhipment ports, where vessels from the Far East call to unload their cargoes.

According to recent studies (Ferrari et al. [14]), Genoa could represent a more profitable access way for goods heading to Central and Northern Europe than North European ports.

Comparing maritime distances and days of navigation between Singapore Rotterdam route and Singapore - Genoa (via North African ports), the latter turns out to be preferable with benefits of up to $20 \%$.

That is to say, the Port of Genoa may be an optimal linkage between the European continent and cargoes crossing the Mediterranean Sea.

Shifting from theoretical studies to concreteness; these bright hypotheses must be supported by infrastructural innovations and ICTs' progression. The MoS 24 Project could be the key for a significant step forward in order to realize this scenario on a virtual and communicative side.

The effective chance for better integrating the city into the European transportation network and enhancing its role as one of the most important port in Europe is one of the main reasons why the project has been conceived and carried out by Genoa Port Authority as a leading partner.

Accomplishment of the Project would allow Genoa to become a Co-modality Promotion Center both on a national and international scale, efficiently linked with the European logistics network. 
Focusing on the Italian transportation market, it would mean combining ICT systems already operating within various transport sectors (i.e. road, rail and maritime ones), still independent or not well integrated, such as:

- $\quad$ E-Port (Genoa’s Port Community System);

- UIRNet (Italian National Platform for integrated logistics and intermodal transport);

- Vessel Traffic Service (VTS is a national-wide system covering all the Italian coast and designed to improve the safety of vessel traffic and to protect the environment) (Pinasco et al. [13]);

- $\quad$ Rail systems used by project's partners.

The result would be a more complete service available for customers and transport operators.

Furthermore, it would allow better traffic-flow management and more ecosustainable transport. It would be an indisputable step forward towards a more environmentally-friendly way of transport.

A priority goal is indeed enhancing maritime and rail links rather than road ones. The city of Genoa would take direct advantage from this as it would lead to a more efficient in/out cargoes' management within the urban area and an increase in traffic flow to and from the port.

\subsection{An inside glance}

In February 2013 a survey about the Project's evolution was conducted by the University of Genoa. Its main goal was to obtain a deeper analysis regarding partners' involvement into MoS 24 actions.

It was not focused on technical details or specific skills; rather it was structured in order to get subjective feelings and reflections about the ongoing works.

Personal motivations to take part in the project and issues occurring were highlighted as well through the questionnaire which the Project's partners had to fill during face-to-face or phone interviews.

The main outcomes regarding topics faced so far within this paper (i.e. urban development, network integration and strategies) will be reported in the next section.

\subsubsection{Analysis of outcomes}

Accentuated discrepancies were pointed out about partners' different vision regarding the Project's global utility. Genoa Port Authority conceived the MoS 24 platform as an actual opportunity to enhance not just its role within the local and regional economy, but also, at the same time, with port activities, the city's role and the whole Italian transport network. Similar reflections were provided by institutional bodies taking part in the Project.

In addition, different points of view were shown by other partners; highly desirous to obtain advantages for their own businesses rather than the community. 
GPA's involvement as the most powerful public body within the Project's development was partially criticized as a supposed main cause for too much Genoa-centric evolution during activities.

Despite technical issues and various delays (the platform will not be ready by the presumed ending date), the project is taking shape in a concrete way. That is to say, touchable feedback has been obtained so far, such as that of the demonstrator. A limited number of participants and a reasonable geographical extension are possible reasons to explain this positive feature.

Common doubtful feelings regarding application of a future project have been expressed by many partners. Not about the Project's accomplishment, where activities are proceeding smoothly, but regarding its future use. That is to say, how the platform will be perceived and utilized by the transport community.

The main worry is that a state-of-the-art service will be underestimated and maximum use of its potentialities will not be made. This widespread feeling is mainly due to the current condition of the Italian transport network; still foggy and uncertain because of relevant lacks and disagreements within national development plans regarding logistics and the infrastructural system.

\section{Conclusions}

Last reflections (see 3.3.1) clearly highlight how ICTs alone are not enough for a dramatic enhancement of transport networks. They must be supported by an efficient infrastructural system and the strong will of political bodies to promote institutional policies aimed at facilitating trade.

Cooperation between technological bodies and infrastructure-related and institutional ones would be desirable to maximize results and provide a more complete service.

Since network and integration are the key words for current transport economy, communicating as smoothly as possible with other market players is essential to run and enlarge a business.

The studied case shows how specific ICTs can further enhance transport chains and speed up procedures leading to better management of activities which directly involves entire cities and their economies.

\section{References}

[1] Verhoeven, P. 2009. A review of Port Authority functions: towards a renaissance? International Association Maritime Economists (IAME) Conference, 2009.

[2] Notteboom, T. and J. P. Rodrigue, 2005. Port Regionalization: towards a new phase in port development. Maritime Policy \& Management, 2005, vol. 32, No, 3, 297-313

[3] Notteboom, T. and J. P. Rodrigue, 2009. Re-assessing port-hinterland relationships in the context of global commodity chains. Inserting PortCities in Global Supply Chains. 
[4] Ducruet, C. and T. Notteboom, 2010. The worldwide maritime network of container shipping: Spatial structure and regional dynamics. GaWC Research Bulletin No. 364, published in "Global Networks".

[5] Haralambides, H., 2012. Ports: Engines for Growth and Employment. European Ports Policy Review, Bruxelles, September $25^{\text {th }} 2012$.

[6] Campanai, M., R. Rosini and F. Fioravanti, 2007. EDI and Cargo Flows in the Mediterranean Sea. Proceedings of the Workshop on Multimodal Transport and ICT: Results and Recommendations.

[7] Navarro, C., E. P. Garcia, J. M. L. Lopez, M. G. Sanz, M. L. Escamilla, M. Llop and S. Furio', 2011. Environment for the application of ICT Technologies in European Ports. Best Practice Guide on Single Window, e-Maritime and Port Community System. Port integration, November $23^{\text {rd }}$ 2011.

[8] European Port Community Systems Association, 2011. How to develop a Port Community System.

[9] United Nations - Economic Commission for Europe, 2005. Recommendation and Guidelines on establishing a Single Window. Recommendation No. 33.

[10] Koh Tat Tsen, J., 2011. Ten years of Single Window implementation: lessons learned for the future. Discussion paper presented at Global Trade Facilitation Conference 2011.

[11] Port Authority of Genoa, 2011. The European Project MoS 24. ICT Based Comodality Promotion Center for integrating PP24 into Mediterranean MoS. MoS 24 brochure.

[12] European Commission, 2013. Welcome to the TEN-T Executive Agency. [online] [viewed 23/07/2013]. Available from: http://tentea.ec.europa.eu/

[13] Pinasco, M. et al., 2011. MOS 24 - Survey on ICT Systems in use along TEN-T network.

[14] Ferrari, C., F. Parola and A. Tei, 2011. Northern Africa and International Trade Networks: Port Investments and Market Opportunities.

[15] Wikipedia, 2013. Europe satellite orthographic. [online][viewed 31/07/2013]. Available from: http://it.wikipedia.org/wiki/Europa 